\title{
37,X/38,XY Mosaicism in a Cryptorchid Bengal Cat with Müllerian Duct Remnants
}

\author{
Orsolya Balogh $^{a} \quad$ Alice Berger ${ }^{a} \quad$ Aldona Pieńkowska-Schelling ${ }^{d}$ \\ Florian Willmitzer $^{\mathrm{b}} \quad$ Paula Grest $^{\mathrm{c}} \quad$ Fredi Janett $^{\mathrm{a}} \quad$ Claude Schelling $^{\mathrm{a}}$ \\ Iris M. Reichler ${ }^{\mathrm{a}}$ \\ ${ }^{a}$ Clinic of Reproductive Medicine, ${ }^{b}$ Department of Small Animals, Clinic of Diagnostic Imaging, and ${ }^{\mathrm{C}}$ Institute of \\ Veterinary Pathology, Vetsuisse-Faculty, University of Zurich, Zurich, and IInstitute of Genetics, Vetsuisse-Faculty, \\ University of Bern, Bern, Switzerland
}

\section{Key Words}

Intersex $\cdot$ Male $\cdot$ Karyotype $\cdot$ Testis $\cdot$ Tomcat .

Sex chromosome DSD $\cdot$ SRY

\begin{abstract}
A 23-month-old tomcat was referred to our clinic because of male behavioral problems, cryptorchidism, and an undefined intra-abdominal organ resembling a uterus. Ultrasonography and computed tomography showed 2 fluid-filled tubular structures dorsolaterally to the bladder and connected to the pelvic urethra. The cat was castrated, and the tubular structures were surgically removed. Histology identified them as Müllerian duct remnants. The testes were hypoplastic, the epididymes and deferent ducts were normal. Cytogenetic analyses revealed the presence of a mosaic $37, \mathrm{X} / 38, \mathrm{XY}$ karyotype which explains the clinical findings.
\end{abstract}

(c) 2016 S. Karger AG, Basel

Normal sexual development in mammals is a multistep process that includes the establishment of chromosomal, gonadal, and phenotypic sex. Impairment in any of these pathways leads to abnormal sexual development [Lyle, 2007; Meyers-Wallen, 2009]. Recently, new classification systems for disorders of sexual development (DSD)

\section{KARGER}

(c) 2016 S. Karger AG, Basel

$1661-5425 / 16 / 0000-0000 \$ 39.50 / 0$

E-Mail karger@karger.com

www.karger.com/sxd taking molecular diagnostics into account were published for cats and dogs [Poth et al., 2010; Meyers-Wallen, 2012], following a classification proposed for humans [Pasterski et al., 2010] with the consensus terminologies of sex chromosome DSD, XY DSD and XX DSD.

Sex chromosome DSD are a result of aberrant sex chromosome structures or numbers, which arise from fusion of 2 zygotes in the case of XX/XY chimera or nondisjunction of chromosomes within the same individual including XXY and variants, XXX and variants, monosomy $\mathrm{X}$ and variants, and $\mathrm{X} / \mathrm{XY}$ (mixed gonadal dysgenesis). An overview on the different types of sex chromosome DSD in domestic cats has recently been published [Meyers-Wallen, 2012]. Phenotypic male cats with a $39, \mathrm{XXY}$ karyotype or its mosaic variants $38, \mathrm{XY} / 39, \mathrm{XXY}$ and 38,XY/39,XYY [Centerwall and Benirschke, 1975; Moran et al., 1984; Leaman et al., 1999; Schmidt-Küntzel et al., 2009; Pedersen et al., 2014] as well as tomcats with $38, \mathrm{XX} / 38, \mathrm{XY}$ chimeric karyotypes [Centerwall and Benirschke, 1975; Moran et al., 1984; Leaman et al., 1999; Long, 1999] may only be found if they have unusual tortoiseshell or calico coats. Cats with monosomy $\mathrm{X}$ and variants as well as XXX and variants are phenotypic fe-

\section{C.S. and I.M.R. contributed equally to this work.}

Orsolya Balogh

Clinic of Reproductive Medicine

Vetsuisse-Faculty, University of Zurich

Winterthurerstrasse 260, CH-8057 Zurich (Switzerland)

E-Mail obalogh@vetclinics.uzh.ch 
Fig. 1. Positive retrograde CT urethrogram. a Transverse image showing contrast media in each horn $(\mathrm{H})$ of the Müllerian duct remnants with connection to the ipsilateral testis. b The sagittal view (thick slap reconstruction) shows both horns of the remnant ducts converging into a body (B), which ends in the urethra at the level of the pelvic symphysis (white arrow).
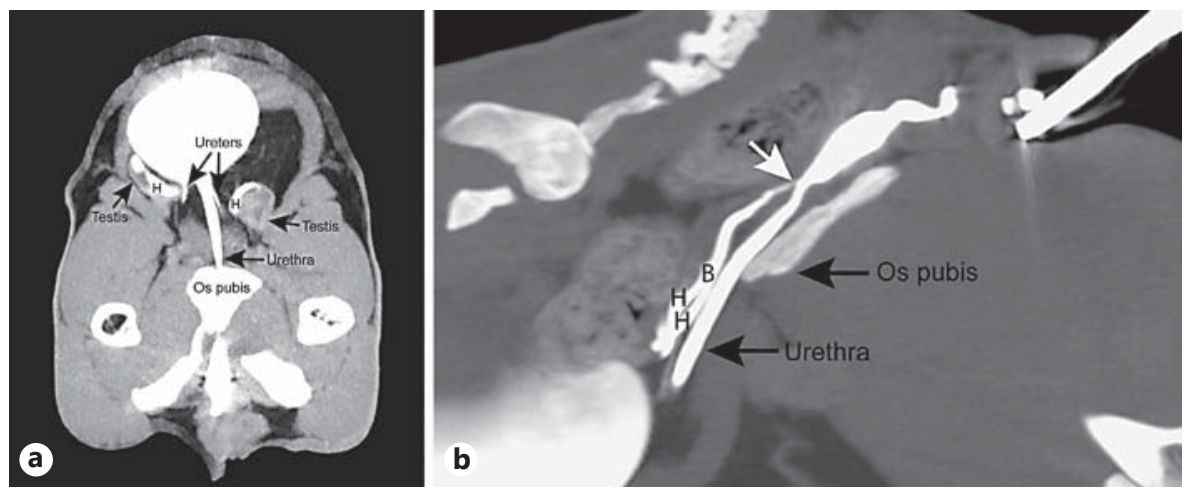

males [Norby et al., 1974; Long and Berepubo, 1980; Johnston et al., 1983; Manna and Sarkar, 1988]. Pregnancy and unilateral ovarian dysgenesis were reported in 2 queens with the mosaic karyotypes $37, \mathrm{X} / 38, \mathrm{XX}$ and 37,X/39,XXX [Dybdahl Thomsen et al., 1987]. X/XY mosaicism was reported in 1 dog only [Giger et al., 1989; Smith et al., 1989] and has not yet been described in cats. However, some cases of feline DSD found in the literature lack detailed cytogenetic and molecular analysis; therefore, the recently published DSD classification is not possible and $\mathrm{X} / \mathrm{XY}$ mosaic cases might have been missed.

The present report describes a cryptorchid cat with Müllerian duct structures and a mosaic 37,X/38,XY karyotype.

\section{Materials and Methods}

\section{Animal}

A 23-month-old Bengal tomcat was referred to our clinic with male behavioral problems, i.e. aggressiveness and urine marking, suspicion of abdominal cryptorchidism, and because of an undefined intra-abdominal organ resembling a uterus noted during exploratory laparotomy by the referring veterinarian. On presentation, an inguinal right and a prescrotal left testis were found. The penis and prepuce were normal, and the penis had spines. Hematology, blood chemistry, and urinalysis were unremarkable, urine culture was negative. Serum was collected for testosterone (IDEXX Diavet AG, Bäch, Switzerland) and AMH analysis (Laboklin, Basel, Switzerland). Azoospermia was diagnosed after semen collection by electroejaculation. The ejaculated fluid contained high numbers of inflammatory cells. Ultrasonography, plain and positive retrograde enhanced computed tomography (CT) was carried out to identify and localize the intra-abdominal structure suspected to be a uterus masculinus. Bilateral orchiectomy and laparotomy were performed, and the removed organs including both testes and the suspected uterus masculinus were fixed in $10 \%$ neutral phosphate-buffered formalin, embedded in paraffin, and examined histologically.
Cytogenetic and Molecular Analyses

Full EDTA- and heparin-treated blood was collected and used for molecular and cytogenetic analysis, respectively. In addition, buccal cells were collected using cotton swabs. The mucosal cells were rinsed in physiological $0.9 \% \mathrm{NaCl}$, centrifuged, and after resuspension of the pellet, fixed 3 times in methanol/acetic acid. High molecular weight genomic DNA was isolated using a proteinase K/phenol extraction method. PCR amplification of the SRY gene from genomic DNA was performed using a primer pair described in Ciani et al. [2008], which results in a 164-bp amplification product. Chromosomes were prepared according to standard protocols from short-term lymphocyte cultures. QFQ-staining of the metaphase chromosomes followed the method described by Vosa [1971]. More than 300 metaphases were analyzed, and karyograms were prepared according to Ford et al. [1980]. FISH analysis of the Y chromosome was carried out with an in-house developed feline whole Y chromosome painting probe according to standard protocols. This method was applied to more than 400 interphase nuclei of buccal mucosal cells.

\section{Results}

On ultrasonography, a thin-walled, fluid-filled tubular structure was visible in the caudal abdomen and suspected to be in contact with the right inguinal testis. Plain CT identified 2 fluid-filled tubular structures dorsolaterally to the bladder and bilaterally extending into the pelvis, converging at the pelvic inlet similar to a uterine bifurcation. In the retrograde CT urethrogram, iodinated contrast was delineated in both tubular structures, which are presumably the horns of the Müllerian duct remnants, leading each to the ipsilateral prescrotal left or inguinal right testis (fig. 1a). A connection at the level of the pelvic symphysis was identified between the pelvic urethra and the suspected Müllerian duct remnant caudal to the convergence of the horns (fig. 1b).

During surgery, the fluid-filled tubular structures were identified (fig. 2), and their course was followed intra- 


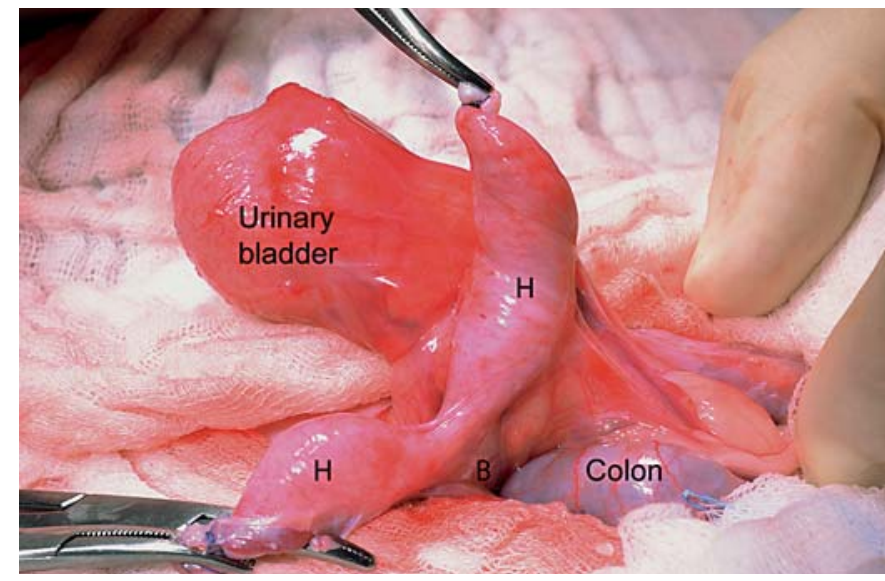

Fig. 2. Intraoperative image of the horns $(\mathrm{H})$ of the Müllerian duct remnants after ligation and removal of both testes. Note that both horns are dilated and they converge into a structure similar to a uterine body $(\mathrm{B})$.

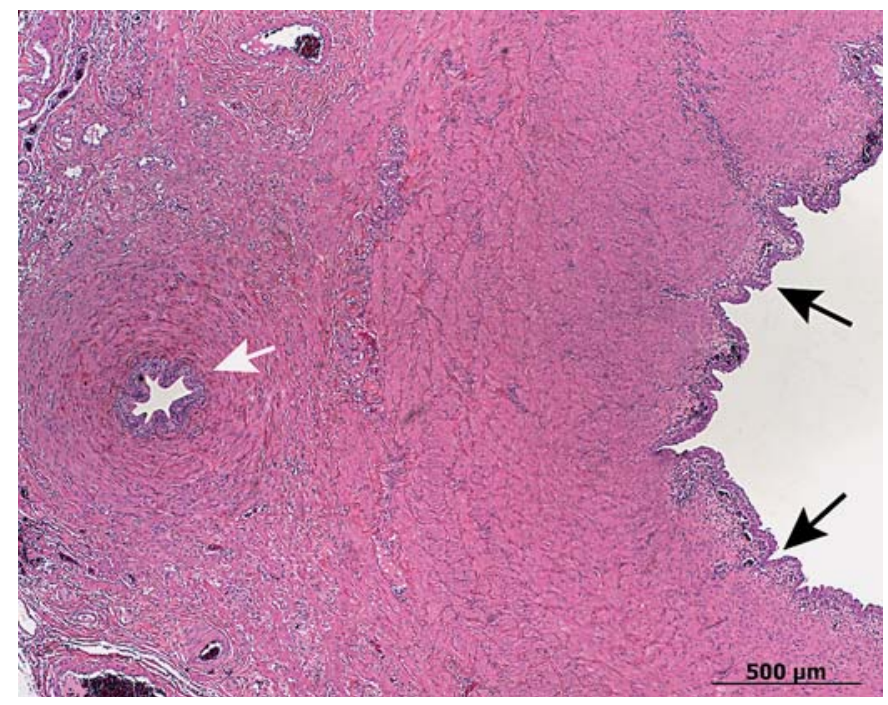

Fig. 3. The Müllerian duct remnant is aligned by stratified epithelium (black arrows) and a muscular layer. The ductus deferens (white arrow) has normal histological structure.

operatively. Both horns ran through the inguinal canal and ended at the caudal pole of the left and right testis. After removal of the left testis through a small inguinal skin incision, the suspected Müllerian duct remnants were bluntly separated from the surrounding tissue using the prescrotal and abdominal approach on the left side, and the abdominal approach on the right side. The right testis and both horns of the suspected Müllerian duct remnants were brought into the abdomen through the

Mosaicism in a Cryptorchid Bengal Cat with Müllerian Duct Remnants

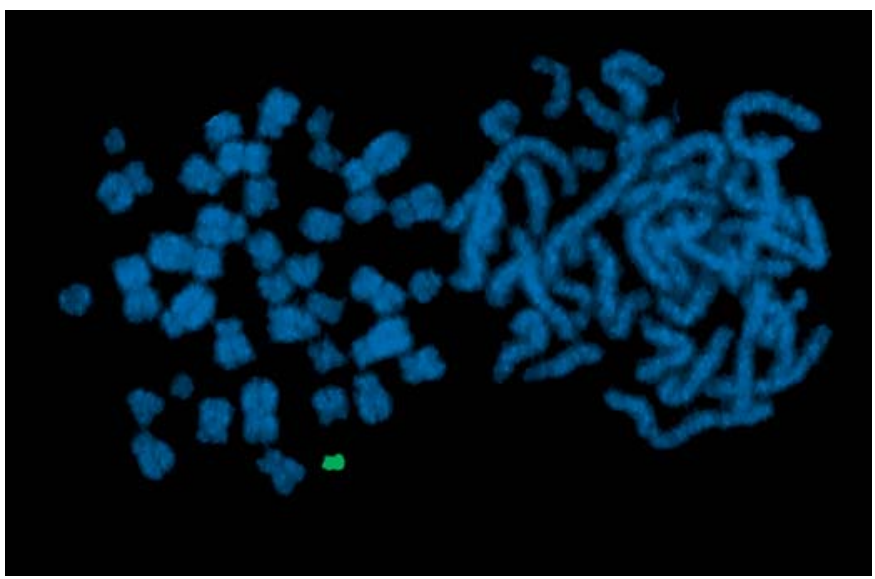

Fig. 4. FISH of 2 metaphases with a feline whole Y chromosome painting probe showing the 38,XY karyotype on the left and 37,X karyotype on the right.

inguinal canals. Surgical excision was performed cranial to the connection of the pelvic urethra with the converging part of the horns. Both inguinal canals, the abdomen, and the inguinal incision were routinely closed. The cat was released from the hospital 2 days after surgery and made a full recovery. The behavioral problems disappeared.

Histology revealed bilateral hypoplastic testes with the presence of Sertoli and Leydig cells and a lack of germ cells. The epididymides and the deferent ducts were normal. On both sides, merged with the deferent duct, a tubular structure with a tunica muscularis layer and a lining consisting of a stratified epithelium was present (fig. 3), containing few to moderate numbers of degenerate neutrophil granulocytes within the lumen. The histology findings were consistent with Müllerian duct remnants and purulent inflammation. Serum testosterone concentration was $2.2 \mathrm{ng} / \mathrm{ml}$ (laboratory reference value for mature, intact tomcats: $0.3-4.0 \mathrm{ng} / \mathrm{ml}$; neutered males: $<0.1$ $\mathrm{ng} / \mathrm{ml}$ ) and $\mathrm{AMH}$ was $18.48 \mathrm{ng} / \mathrm{mL}$ (laboratory reference range for adult, intact tomcats: $>3.0 \mathrm{ng} / \mathrm{ml}$; neutered males: $<0.5 \mathrm{ng} / \mathrm{ml}$ ).

The cat showed a mosaic 37,X/38,XY karyotype. The 2 cell lines were found in 96 and 4\% of the lymphocytes, respectively. Representative metaphases after FISH with the Y chromosome painting probe are shown in figure 4. The autosomes and both sex chromosomes of the cat appeared normal with no visible structural aberrations. The result after FISH with the Y chromosome painting probe on interphase nuclei was similar. A 164-bp fragment of the SRY gene could be successfully amplified from ge- 
nomic DNA of the cat (not shown). The PCR product had a $100 \%$ homology with the feline SRY sequence (GenBank accession no. DQ095188.1)

\section{Discussion}

In cats, DSD is most often an incidental finding at the time of spay or neuter [Dybdahl Thomsen et al., 1987; Bredal et al., 1997]. Rarely, cats are presented because of fertility problems, clinical signs related to malformations of the reproductive organs, or because of behavioral problems [Schulman and Levine, 1989; Pedersen et al., 2014; Pieńkowska-Schelling et al., 2015]. The male aggressive behavior of the cat in our case, its penile spines, and the serum testosterone concentration within the wide reference range reported for intact, adult male cats [Johnstone et al., 1984; Johnston et al., 1996; Tsutsui et al., 2009] indicated the presence of testes. However, detection of the fluid-filled uterine horn-like structures and the bilateral cryptorchid location of the testes supported the possibility of DSD. Therefore, cytogenetic analyses and molecular analysis for the presence of the Sry gene were carried out. Because the intraabdominal uterus-like structure was suspicious for Müllerian duct derivatives, serum $\mathrm{AMH}$ was also measured.

The 37,X/38,XY mosaic karyotype found in this cat belongs to the group of sex chromosome DSD, which has been reported in small companion animals only once in a dog with ambiguous external genitalia, one grossly normal and a remnant uterine horn, and only interstitial cells in the abdominal gonads [Smith et al., 1989]. 77,X/78,XY gonadal mosaicism was assumed [Giger et al., 1989; Meyers-Wallen, 2012] even though the author describing the case only found a 77,X karyotype. In our tomcat, FISH with a whole $\mathrm{Y}$ chromosome painting probe revealed a low level mosaicism with only $4 \%$ of the lymphocytes showing a $38, \mathrm{XY}$ and $96 \%$ showing a $37, \mathrm{X}$ karyotype. In humans with 45,X/46,XY mosaicism, varying frequencies of the cell lines are described, i.e. $45, \mathrm{X}$ cells ranging between 10-96\% [Rosa et al., 2014], but no correlation between the proportion of $45, \mathrm{X} / 46, \mathrm{XY}$ cell lines in the blood and the phenotype has been reported [Telvi et al., 1999; Tosson et al., 2012]. The proportion of a cell line in the undifferentiated gonad determines its development [Berkovitz, 1992; Telvi et al., 1999], e.g. in human $45, \mathrm{X} / 46, \mathrm{XY}$ mosaicism, both $45, \mathrm{X}$ and $46, \mathrm{XY}$ cell lines were consistently found in variable percentages in testes and blood lymphocyte cultures, while in streak gonads only the 45,X cell line was present [Telvi et al., 1999; Tos- son et al., 2012]. The karyotype of the gonads in our case was not determined, but the finding of testes, even though in cryptorchid location and without germ cells, suggests the presence of the 38,XY cell line in the undifferentiated embryonic gonads. However, the number of 38 , XY cells was probably not sufficient for normal expression of the Y-linked SRY gene, which must overcome a threshold during the critical time window to successfully induce the testis pathway [DiNapoli and Capel, 2008; Meyers-Wallen, 2009].

In humans, 45,X/46,XY individuals show wide phenotypic variation including normal male phenotype with normal male genitalia and testis [Telvi et al., 1999], abnormal male external and internal genitalia (e.g. hypospadias, cryptorchidism, streak or dysgenetic gonads, Müllerian duct derivatives), as well as anomalies of other organs [Chang et al., 1990; Telvi et al., 1999; Farrugia et al., 2013; Rosa et al., 2014]. Persistent Müllerian structures were also found in our cat and are indicative of a failure of AMH function during the critical window of embryonic development. AMH is normally produced by Sertoli cells of the fetal testis and initiates regression of the Müllerian (paramesonephric) ducts. Defects in its production or insensitivity to it may result in persistent ducts [Josso et al., 2001]. Since AMH serum concentration in the cat ( 18.48 $\mathrm{ng} / \mathrm{ml}$ ) was within the reference range of $4.8-81.3 \mathrm{ng} / \mathrm{ml}$ reported for normal, adult, intact male cats [Axnér and Ström Holst, 2015], insensitivity to AMH during in utero development may be possible. In a breeding experiment in Miniature Schnauzers on the inheritance of persistent Müllerian duct syndrome, which is an XY DSD, AMH immunoreactivity in the testes of affected pups was similar to normal littermates, and the bioactivity of the hormone was also comparable in the 2 groups [Meyers-Wallen et al., 1989], indicating rather a receptor insensitivity. Indeed, a malfunction of the AMH type II receptor caused by a single base pair mutation was found responsible for the failure of the Müllerian ducts to regress in the offspring of Miniature Schnauzers with persistent Müllerian duct syndrome [Wu et al., 2009]. Hypothetically, a defect in the $\mathrm{AMH}$ receptor or in its downstream signaling might as well explain the lack of Müllerian duct regression in our $\mathrm{X} / \mathrm{XY}$ mosaic case. However, persistence of the Müllerian ducts can also be due to delayed or insufficient AMH secretion during the critical time of embryonic development as discussed in canine testicular DSD, i.e. XX sex reversal [Meyers-Wallen et al., 1987, 1994].

The normal-sized penis and histologically normal epididymis and vas deferens of our cat indicate androgen exposure in utero, as stabilization of the Wolffian ducts 
and masculinization of the urogenital sinus, genital tubercle, and genital swellings during the critical embryonic period is dependent on secretion of testosterone and its conversion to dihydrotestosterone [Lyle, 2007; Meyers-Wallen, 2009]. Insufficient secretion of hormones by the hypoplastic testes may explain the cryptorchid inguinal and prescrotal location. Because transabdominal migration was complete, failure in fetal Leydig cells' production of insulin-like 3 peptide, which appears to be the main regulator in this descensus phase, is less likely compared to testicular androgens, which have indirect and direct roles in the transabdominal and inguinoscrotal phases [Hughes and Acerini, 2008; Meyers-Wallen, 2009; Hutson et al., 2015].

The cytogenetic finding of a $37, \mathrm{X} / 38, \mathrm{XY}$ mosaic allowed clear classification of our case into the group of sex chromosome DSD. Similar clinical characteristics, i.e. ambiguous or male external genitalia, cryptorchidism, and Müllerian duct derivatives were already found in cats [reviewed in Romagnoli and Schlafer, 2006, Meyers-Wallen, 2012]. However, without karyotyping, they could also be explained by other DSD.

\section{Acknowledgements}

The authors would like to thank Benita Pineroli for her excellent technical work with the molecular biology part of the analyses. We are grateful for the kind help of Irene Schweizer with the illustrations.

\section{Statement of Ethics}

The authors have no ethical conflicts to disclose.

\section{Disclosure Statement}

The authors have no conflicts of interest to declare.

\section{References}

Axnér E, Ström Holst B: Concentrations of antiMüllerian hormone in the domestic cat. Relation with spay or neuter status and serum estradiol. Theriogenology 83:817-821 (2015).

Berkovitz GD: Abnormalities of gonadal determination and differentiation. Semin Perinatol 16:289-298 (1992).

Bredal WP, Thoresen SI, Kvellestad A, Lindblad K: Male pseudohermaphroditism in a cat. J Small Anim Pract 38:21-24 (1997).

Centerwall WR, Benirschke K: An animal model for the XXY Klinefelter's syndrome in man: tortoiseshell and calico male cats. Am J Vet Res 36:1275-1280 (1975).

Chang HJ, Clark RD, Bachman H: The phenotype of 45,X/46,XY mosaicism: an analysis of 92 prenatally diagnosed cases. Am J Hum Genet 46:156-167 (1990).

Ciani F, Cocchia N, Rizzo M, Ponzio P, Tortora $G$, et al: Sex determining of cat embryo and some feline species. Zygote 16:169-177 (2008).

DiNapoli L, Capel B: SRY and the standoff in sex determination. Mol Endocrinol 22:1-9 (2008).

Dybdahl Thomsen P, Byskov AG, Basse A: Fertility in two cats with $\mathrm{X}$-chromosome mosaicism and unilateral ovarian dysgenesis. J Reprod Fertil 80:43-47 (1987).

Farrugia MK, Sebire NJ, Achermann JC, Eisawi A, Duffy PG, Mushtaq I: Clinical and gonadal features and early surgical management of $45, \mathrm{X} / 46, \mathrm{XY}$ and 45,X/47,XYY chromosomal mosaicism presenting with genital anomalies. J Pediatr Urol 9:139-144 (2013).
Ford CE, Pollock DL, Gustavsson I: Proceedings of the First International Conference for the Standardisation of Banded Karyotypes of Domestic Animals. Hereditas 92:145-162 (1980).

Giger U, Meyers-Wallen VN, Patterson DP: A 6-month-old Doberman pinscher with ambiguous genitalia as a first case of $\mathrm{X}$-chromosomal monosomy in the dog. J Vet Intern Med 3:245 (1989).

Hughes IA, Acerini CL: Factors controlling testis descent. Eur J Endocrinol 159:S75-S82 (2008).

Hutson JM, Li R, Southwell BR, Newgreen D, Cousinery M: Regulation of testicular descent. Pediatr Surg Int 31:317-325 (2015)

Johnston SD, Buoen LC, Madl JE, Weber AF, Smith FO: X-Chromosome monosomy $(37, \mathrm{XO})$ in a Burmese cat with gonadal dysgenesis. J Am Vet Med Assoc 182:986-989 (1983).

Johnston SD, Root MV, Olson PNS: Ovarian and testicular function in the domestic cat: clinical management of spontaneous reproductive disease. Anim Reprod Sci 42:261-274 (1996).

Johnstone IP, Bancroft BJ, McFarlane JR: Testosterone and androstenedione profiles in the blood of domestic tom-cats. Anim Reprod Sci 7:363-375 (1984).

Josso N, di Clemente N, Gouédard L: Anti-Müllerian hormone and its receptors. Mol Cell Endocrinol 179:25-32 (2001).

Leaman T, Rowland R, Long SE: Male tortoiseshell cats in the United Kingdom. Vet Rec 144:9-12 (1999).
Long SE: 38,XX/38,XY chromosome chimaerism in three feline siblings. Vet Rec 145:404-405 (1999).

Long SE, Berepubo NA: A 37XO chromosome complement in a kitten. J Small Anim Pract 21:627-631 (1980)

Lyle SK: Disorders of sexual development in the dog and cat. Theriogenology 68:338-343 (2007).

Manna GK, Sarkar CS: An XO female house cat, Felis catus. Chromosome Info Svc 45:10-12 (1988).

Meyers-Wallen VN: Review and update: genomic and molecular advances in sex determination and differentiation in small animals. Reprod Domest Anim 44:40-46 (2009).

Meyers-Wallen VN: Gonadal and sex differentiation abnormalities of dogs and cats. Sex Dev 6:46-60 (2012)

Meyers-Wallen VN, Donahoe PK, Manganaro T, Patterson DF: Müllerian inhibiting substance in sex-reversed dogs. Biol Reprod 37:10151022 (1987).

Meyers-Wallen VN, Donahoe PK, Ueno S, Manganaro TF, Patterson DF: Müllerian inhibiting substance is present in testes of dogs with persistent Müllerian duct syndrome. Biol Reprod 41:881-888 (1989).

Meyers-Wallen VN, MacLaughlin D, Palmer V, Donahoe PK: Mullerian-inhibiting substance secretion is delayed in XX sex-reversed dog embryos. Mol Reprod Dev 39:1-7 (1994).

Moran C, Gillies CB, Nicholas FW: Fertile male tortoiseshell cats mosaicism due to gene instability? J Hered 75:397-402 (1984).
Mosaicism in a Cryptorchid Bengal Cat with Müllerian Duct Remnants 
Norby DE, Hegreberg GA, Thuline HC, Findley D: An X0 cat. Cytogenet Cell Genet 13:448453 (1974)

Pasterski V, Prentice P, Hughes IA: Impact of the consensus statement and the new DSD classification system. Best Pract Res Clin Endocrinol Metab 24:187-195 (2010).

Pedersen AS, Berg LC, Almstrup K, Thomsen PD A tortoiseshell male cat: chromosome analysis and histologic examination of the testis. Cytogenet Genome Res 142:107-111 (2014).

Pieńkowska-Schelling A, Becker D, Pineroli B, Schelling C: Ein Fall von SRY positive SexUmkehr bei einer Hauskatze. Schweiz Arch Tierheilk 157:157-159 (2015).

Poth T, Breuer W, Walter B, Hecht W, Hermanns W: Disorders of sex development in the dog - adoption of a new nomenclature and reclassification of reported cases. Anim Reprod Sci 121:197-207 (2010).
Romagnoli S, Schlafer DH: Disorders of sexual differentiation in puppies and kittens: a diagnostic and clinical approach. Vet Clin North Am Small Anim Pract 36:573-606 (2006).

Rosa RF, D'Ecclesiis WF, Dibbi RP, Rosa RC, Trevisan P, et al: 45,X/46,XY mosaicism: report on 14 patients from a Brazilian hospital. A retrospective study. Sao Paulo Med J 132: 332-338 (2014).

Schmidt-Küntzel A, Nelson G, David VA Schäffer AA, Eizirik E, et al: A domestic cat X chromosome linkage map and the sex-linked orange locus: mapping of orange, multiple origins and epistasis over nonagouti. Genetics 181:1415-1425 (2009).

Schulman J, Levine SH: Pyometra involving uterus masculinus in a cat. J Am Vet Med Assoc 194:690-691 (1989).

Smith FW Jr, Buoen LC, Weber AF, Johnston SD, Randolph JF, Waters DJ: X-chromosomal monosomy $(77, \mathrm{XO})$ in a Doberman Pinscher with gonadal dysgenesis. J Vet Intern Med 3: 90-95 (1989).
Telvi L, Lebbar A, Del Pino O, Barbet JP, Chaussain JL: 45,X/46,XY mosaicism: report of 27 cases. Pediatrics 104:304-308 (1999).

Tosson H, Rose SR, Gartner LA: Description of children with 45,X/46,XY karyotype. Eur J Pediatr 171:521-529 (2012).

Tsutsui T, Onodera F, Oba H, Mizutani T, Hori T: Plasma hormone levels and semen quality in male cats during non-breeding and breeding seasons. Reprod Dom Anim 44:291-293 (2009).

Vosa CG: The quinacrine fluorescence patterns of the chromosomes of Allium carinatum. Chromosoma 33:382-385 (1971).

Wu X, Wan S, Pujar S, Haskins ME, Schlafer DH, et al: A single base pair mutation encoding a premature stop codon in the MIS type II receptor is responsible for canine persistent Müllerian duct syndrome. J Androl 30:46-56 (2009). 